This item was submitted to Loughborough's Research Repository by the author.

Items in Figshare are protected by copyright, with all rights reserved, unless otherwise indicated.

\title{
An empirical laser sintering time estimator for Duraform PA
}

PLEASE CITE THE PUBLISHED VERSION

PUBLISHER

(C) Taylor \& Francis

VERSION

AM (Accepted Manuscript)

LICENCE

CC BY-NC-ND 4.0

\section{REPOSITORY RECORD}

Ruffo, M., Christopher Tuck, and Richard J.M. Hague. 2019. "An Empirical Laser Sintering Time Estimator for Duraform PA". figshare. https://hdl.handle.net/2134/5655. 
This item was submitted to Loughborough's Institutional Repository (https://dspace.lboro.ac.uk/) by the author and is made available under the following Creative Commons Licence conditions.

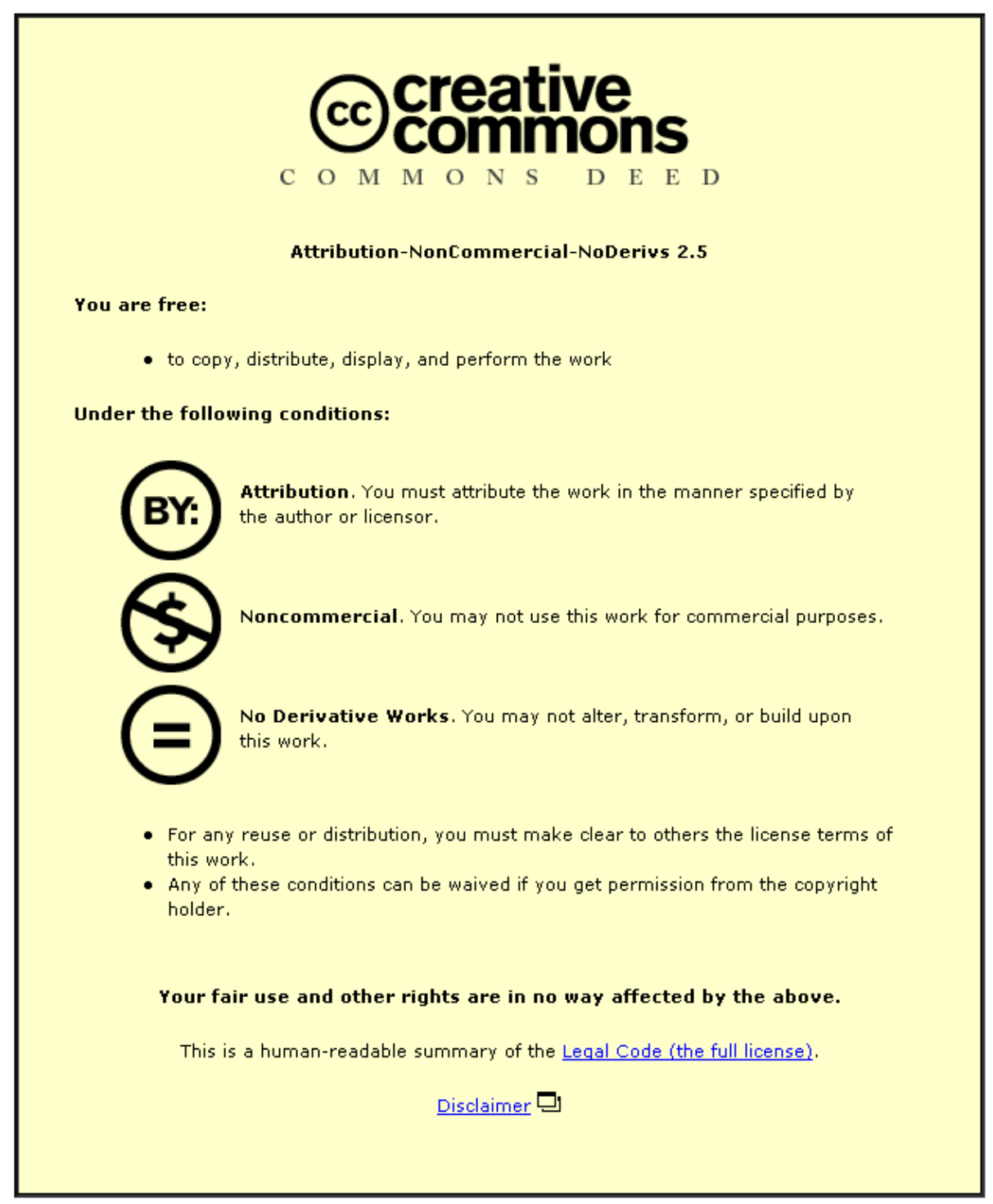

For the full text of this licence, please go to: http://creativecommons.org/licenses/by-nc-nd/2.5/ 


\title{
An Empirical Laser Sintering Time Estimator for Duraform PA
}

\author{
MASSIMILIANO RUFFO †*, CHRISTOPHER TUCK† and RICHARD HAGUE†
}

\begin{abstract}
This paper presents work on the development of a build time estimator for Rapid Manufacturing (RM). A time estimator is required in order to develop a comprehensive costing tool for RM. An empirical method has been used to estimate build times utilising both simulated and actual builds for a Laser Sintering (LS) machine. The estimator presented here is based upon object geometry and therefore the fundamental data driving the model is obtainable from current three dimensional Computer Aided Design (3D-CAD) models. The aim of the paper is to define a model describing the build times for a laser sintering machine either for single or multiple objects.
\end{abstract}

Keywords: Rapid Manufacturing; Time estimation; Laser Sintering; Rapid Prototyping; Cost estimation

\section{Introduction}

The term Rapid Prototyping (RP) is used for all techniques that allow the realisation of models by the addition of material layer by layer, starting from a 3D-CAD model. Differently from traditional machining, which work by subtracting material from a block of material, RP systems manufacture layers from liquid, powder, filaments, rolled and spooled materials (Wohlers T. 2004). Layer after layer, these machines reconstruct the object represented by a 3D-CAD model once an additional software has sliced the 3D-CAD model. When such production technology is used to produce end-use parts, it is also known as Rapid Manufacturing (RM) (Hopkinson and Dickens 2001). RM is able to exploit the concept of 'freedom of design', because tooling is no longer required. Many of the issues experienced with traditional manufacturing technology, such as split lines, draft angles, undercuts and thin wall sections in injection moulding, are removed. This allows designers to develop more imaginative and creative work (Hague et al. 2003).

The evolution of market requirements during the last ten years has introduced the need for faster product development and a reduced time to market (Kochan 2003A). This

† Rapid Manufacturing Research Group, Wolfson School of Mechanical and Manufacturing Engineering, Loughborough University, Leicestershire, LE11 3TU, UK

* Corresponding author. Email: M.Ruffo@lboro.ac.uk 
evolution, connected with the tendency to move towards customisation is leading the diffusion of RM as a production method.

RM is currently being used by numerous companies, such as Renault Formula One (Kochan 2003B), Rocketdyne (Sherman 2005) and Siemens Hearing Instruments (Plastic 2005) for the production of end-use parts. One of the issues for further uptake of RM is the economy of the processes. RM machines are still expensive due to the technology being in its infancy.

Of the current range of RM processes, Laser Sintering (LS) appears to be the most appropriate for RM. In fact, the materials used in LS have better mechanical properties compared with most of the other RM materials (Wohlersassociates 2005). Moreover, in the LS process, support structures are not necessary because the initial state of the material is a powder and this makes the build self supporting and it allows the production of multiple parts in the vertical direction. This property gives to the LS process the highest usable capacity for a given bed volume (Hopkinson and Dickens 2003). For the reasons exposed, this study has been based on a 3D-Systems ${ }^{\mathrm{TM}}$ Vanguard LS machine (3Dsystems).

Production costs are fundamental for any enterprise and to be able to estimate them as accurately as possible is a necessity. RM machine investment heavily influences the final cost of products (Grimm T. 2004), which adds an indirect cost not omissible in a costing model. This investment must be absorbed by production and, as RM systems can build different parts that require different build times, a method to assign indirect costs could be based on time. Therefore, it is fundamental to have appropriate time estimation in order to calculate production costs.

When talking about Rapid Manufacturing, a common phrase used is 'design is free'; however, this is not always correct. Specifically, for processes such as jetting-based systems, the "freedom of design" statement is true; conversely it is not correct for laserbased systems which have to trace out the cross section profile with laser beam. In consequence, for the laser manufacturing processes, build times are higher for complex shapes than for simple shapes.

The aim of this paper is to show which of the main geometric parameters affect the time for LS. A second objective is to find the relationship defining the build time through the simplest geometric variables of the part. It is fundamental to have simple variables guiding the model because they will be cost drivers if the time estimator is implemented in a costing model.

\section{State of the art}

Most conventional RP build time predictors are based on equations derived statistically as a function of the total part volume, as reported by Kamash and Flynn (1995). Other estimators are based on the function of the total scan length that the laser travels. Chen and Sullivan (1996) studied Stereolithography systems and defined a new function for the build time estimation, including new factors such as laser power, beam diameter, material properties and the user's specification of cure depth.

Recently, a new build time estimator was studied in order to complete a virtual reality system able to model and simulate a LS process. The authors of the study, Choi and Samavedam (2002), firstly identified the key parameters analysing previous papers on the identification of factors, such as laser power and velocity (Diane et al. 1997, Zhou and 
Hersovici 1997, Thomson and Craword 1995). Choi and Samavedam analysed many software that were able to place parts on the bed in an efficient orientation (Thomson and Craword 1997, Woodzaik et al. 1994, Marsan et al. 1997), and finally they tried to create a model able to manage all the main parameters together. In their paper, Choi and Samavedan (2002) affirm that orientating a part in the minimum z-height results with minimum build time. However, this is disputable in the case of multiple parts. For example, when the machine bed is full of parts, their orientation does not affect the build time as the total height does not vary. In general, part orientation only affects the build time in a configuration in which its height modifies the total build height. Choi and Samavedam's (2002) build time estimator for the LS process evaluates the time as a function of laser velocity, scan distance and layer thickness, arriving at complex equations that are not only difficult to understand but also to use.

\section{Methodology}

This paper uses a different approach to time estimation in respect of previous articles found in the literature. Previous estimators were based on the microanalysis of timing, describing the process in detail, starting the study from the laser speed and falling inevitably to complex equations. This paper presents a macro-analysis of the problem, arriving at functions controlled by simple geometric parameters of the objects to be built.

In RP build time estimation there are many variables and so many different conditions that it is difficult to predict them perfectly. Therefore, it is incorrect to estimate a micro-variable (such as laser speed) when there are other macro-variables destroying the precision of the estimation. In other words, it is inconvenient to estimate precisely the smallest part of the process (i.e. a small laser head movement) when there are bigger errors in other parts of the process (i.e. waiting times related to material heating).

The method used has been to "reverse engineer" the estimation problem defining the inputs and the output in order to discover the model, initially seen as a black box. The

model could be described by a series of relationships leading to a time (output), starting from some geometrical variables (inputs), as shown in Figure 1.

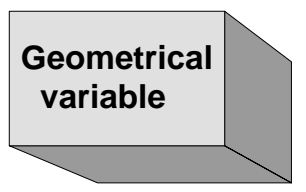

Figure 1. The problem seen as a black box 
The crux of the study is to find the right inputs and outputs and to use them inconjunction to define the model. The inputs must be simple geometrical variables and it is important to understand which has more effect than others. The output is the time resulting from a real build. The methodology of approximating functions from results needs a wide number of different samples. Building sample parts is both time and money consuming; therefore, the initial approach used was to obtain build times from software which drives the LS machine, called Build Setup ${ }^{\mathrm{TM}}$ ver3.4. The variables utilised in the software were the default settings and the material used for the entire study is Duraform PA - a nylon 12 material. A further step was to empirically validate the results through data obtained from actual builds.

It is incumbent to specify the reasons of a need of a time estimator instead of using directly the Build Setup ${ }^{\mathrm{TM}}$ software. Firstly, the software is usually sold in a bundle with a LS machine, so it could be difficult to obtain build times for non-users. Secondly, the software calculation seems to be accurate due to the simulation of all the processes, starting by slicing the part and calculating the laser trajectory and its speed. This accuracy is balanced by the poor speed of the estimation, even when the software is installed on fast computers. Thirdly, it is necessary to define the part position with respect to the machine bed, and, in the case of multiple parts, the procedure is slow and requires a skilled operator with software knowledge. Finally, this software often underestimates the real time due to the lack of a temperature adaptation time (explained in detail later), and this is risky if the time estimation is used for costing purposes, as it could lead to a cost underestimation.

\subsection{Methodology guidelines}

During this study the word "experiment" has been used to identify a simulation of a LS build through the Build Setup software. Only in two steps of the study, named validations, does the term experiment identify a real build process. Its aim is to prove the accuracy of both the software and the mathematical model extracted from it. A series of steps defining the research methodology follows:

1. Understanding of the LS process - A series of experiments with simple shapes of different size

2. Influence of the shape on build time - Experiments focused on changing the object shape keeping other geometric variables constant in order to understand the main geometric parameters affecting the build time

3. Identification of model drivers - Experiments to understand which are the simplest variables describing the model

4. Validation of experimental results - Replication of the most significant simulations for real, producing physical objects on the LS machine; this is in order to check the differences between simulation software and actual results

5. Extraction of the mathematical model - After the experimental phase (points 1 to 4) the data was used to create the mathematical model

6. Validation of the empirical model - Using real build times obtained from point 4, it is possible to compare them with the results of the empirical model created in point 5 
The model presented later in this study is constructed by approximating functions based on empirical data. During this study, around 40 objects of different size and shape were used, plus combinations to simulate multiple objects. Figure 2(a-c) shows some of the objects used; it represents a group of objects of the same volume and height, created to study points 2 and 3 of the methodology listed above. Complex shapes were also included, such as a chain link structure (Figure 3).

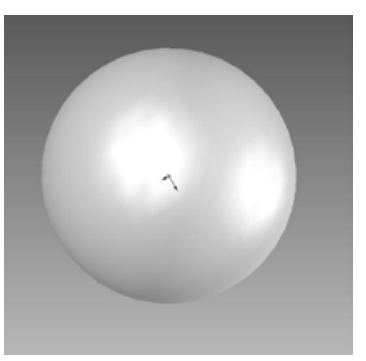

(a)

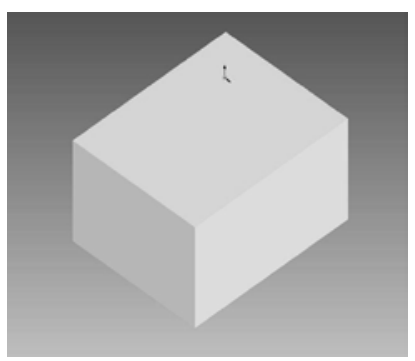

(b)

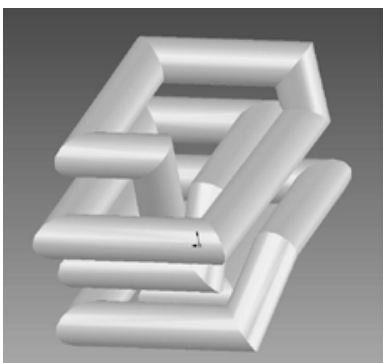

(c)

Figure 2. Group of shapes of the same volume and height

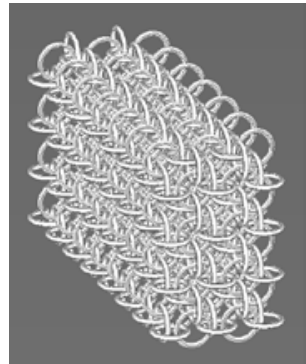

Figure 3. Chain link structure

\section{Experiment results}

\subsection{Understanding the LS process}

Step 1 in the methodology was an understanding of the LS process. Through some experiments on basic shapes, such as boxes of different sizes, it was possible to describe the LS manufacturing process as shown in Figure 4. 
The first part of the process (preparation phase) is based on machine set up, temperature and nitrogen atmosphere preparation and a user defined number of powder layers put down to achieve the correct bed temperature. These three processes do not depend on any geometric data and for this reason they will be considered constant in this study. In reality they are not invariable but they depend on environmental conditions (i.e. external temperature). However, the differences that depend on external conditions is not significant and so the assumption to use a constant value should not introduce a considerable error.

The second part of the process is the "build phase", which is the iteration of three sub-processes:

- Area scanning - The laser melts a section of the two dimensional geometry obtained from slicing the 3D-CAD file of the build 
- Border scanning - The laser defines the perimeter of the build section in order to have a better accuracy on the final surface area

- Recoating - The bed moves down, $0.1 \mathrm{~mm}$ of powder is laid on the previous layer and it is then ready to be sintered

All of these three sub-processes depend on the geometric data from the 3D-CAD model. The actual layer thickness for the LS processes is $0.1 \mathrm{~mm}$; as such, the number of iterations of the build phase is 10 times the height of the bed, measured in millimetres.

The third and final part of the process is the cooling phase. In order to have gradual cooling of the parts in the bed, some layers of powder (a number decided by the user) are put down. Moreover, the entire bed could stay in the machine for a supplementary time in order to have a slower temperature decrease to control distortions. As with the first part of the process, this phase can be assumed constant.

\subsection{Influence of different shapes}

Intuitively, there are two variables directly influencing build time:

- Height - Directly related to the recoat process

- Volume - Directly related to the area scan process

Neither of the two variables can describe the border scan process. The longer and more fractionated the border, the longer the time to complete this task. For example (referring to shapes in Figure 2), when two objects have the same volume and height but one of them needs more time to be scanned, it is mainly due to border scanning (see Scan times in Table 1).

\begin{tabular}{|l|c|c|c|c|c|c|c|}
\hline \multicolumn{1}{|c|}{ OBJECT } & \multicolumn{9}{|c|}{ Geometry } & \multicolumn{3}{c|}{ Times (sec) } \\
\cline { 2 - 9 } & $\begin{array}{c}\text { Volume } \\
(\mathbf{m m})\end{array}$ & $\begin{array}{c}\text { Surface Area } \\
\left.\mathbf{( m m}^{\mathbf{2}}\right)\end{array}$ & $\begin{array}{c}\text { Height } \\
\mathbf{( m m )}\end{array}$ & $\begin{array}{c}\text { Bounding box } \\
\text { Volume } \mathbf{( m m}^{\mathbf{3}} \mathbf{)}\end{array}$ & Recoating & Scan & Total \\
\hline Sphere (Figure 2-a) & 65449 & 7853 & 50 & 125000 & 9179 & 1415 & 10594 \\
\hline Cube (Figure 2-b) & 65449 & 9889 & 50 & 65449 & 9318 & 1319 & 10637 \\
\hline Swept Solid (Figure 2-c) & 65449 & 24496 & 50 & 203364 & 8506 & 2049 & 10555 \\
\hline
\end{tabular}

A more complex object implies a longer time to scan the border. Therefore, the third variable must define the complexity of the shape in some way. In reality, the shape complexity not only affects the time connected with border scanning, but also the time connected with area scanning, due to laser jumps to complete the area fill.

Through the same experiments mentioned above it was possible to identify a property of the LS process. When the laser finishes scanning a section, it must move to a predefined position, which is one of the bed corners. The time necessary for this operation is included in the recoating time. Due to this property, enlarging the bounding box volume (defined through Figure 5) has a double effect on the production time, an increase of the scanning time and a reduction of the recoating time, as shown in Figure 6. 


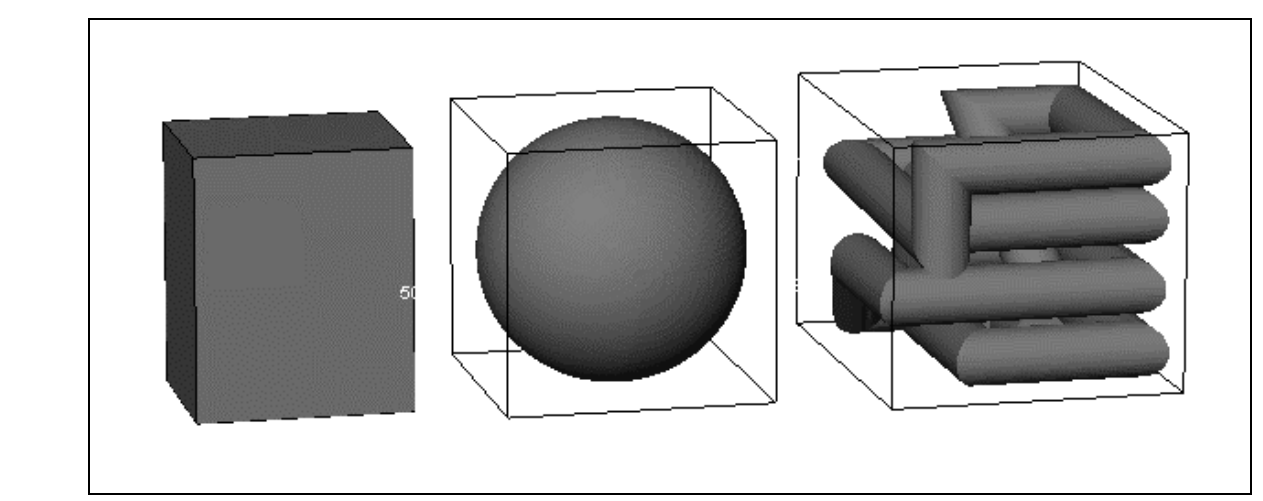

Figure 5. Bounding boxes (or minimum box containing the part) for the three parts of Figure 2

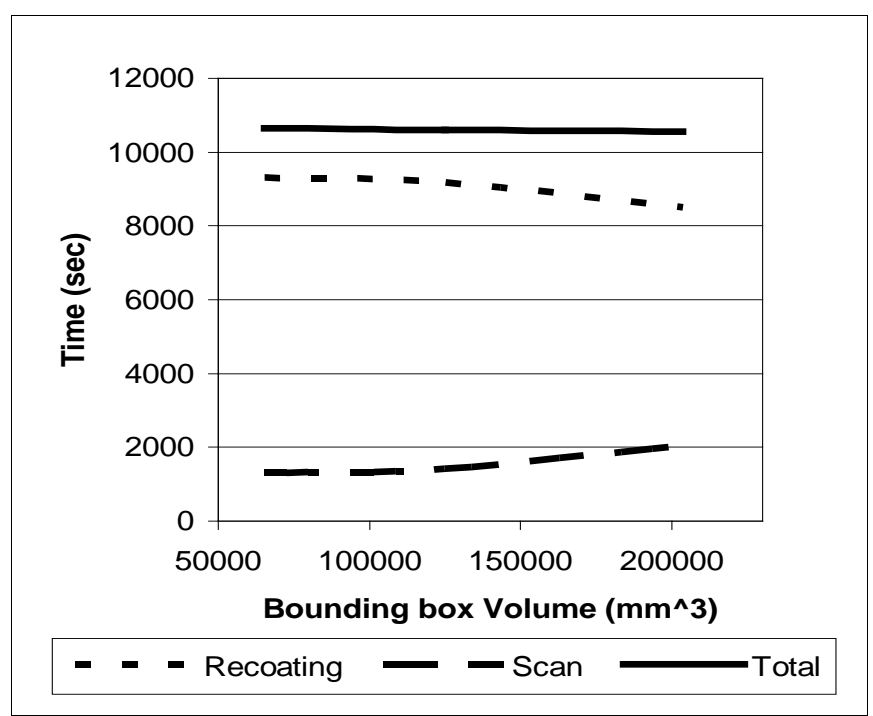

Figure 6. Effect of laser repositioning on the recoating time

\subsection{Identification of model drivers}

As discussed previously, the first two variables driving the model are height and volume. The third parameter must be a function of the shape complexity. Two possible variables describing it are bounding box volume and surface area; both proportional to the part complexity. The surface area was found to be indirectly proportional to the build time. Therefore, for what has been described in section 4.2, the ratio between the bounding box volume and the object volume appears to be one solution to describe the shape complexity. Intuitively, the higher the ratio the more complex the object is. Therefore, the three model drivers are:

- Height

- Volume

- Bounding Box Volume - Influencing area and border scanning and the recoating time, identifying the complexity shape 


\subsection{Experiment results validation}

Fifteen experiments were chosen from the previously described simulations and repeated for real on the Vanguard LS machine. The results evidence precise time estimation in scan and recoating time for the Build Setup ${ }^{\mathrm{TM}}$ software. But the data comparison of warming up and cooling down times for simulated and actual builds is different.

It can be seen in Table 2, where three times of random builds are presented, that the simulation software tends to underestimate the actual build times.

\begin{tabular}{|c|c|}
\hline \multicolumn{2}{|c|}{$\begin{array}{c}\text { Table 2. Comparison between real and simulated times for } \\
\text { three random builds, each one including different components } \\
\text { (HH:MM:SS) }\end{array}$} \\
\hline Actual Time & Simulated Time \\
\hline 8:35:15 & $6: 24: 19$ \\
\hline $26: 20: 18$ & $24: 51: 48$ \\
\hline $29: 38: 46$ & $21: 18: 28$ \\
\hline
\end{tabular}

The cooling down time, in particular, is very different from reality. The reason of the data divergence is based on another time variable that the machine uses to reach the operating temperature; it is called 'wait for temperature' time. The warm up and cool down stages are phases in which the machine adds powder without any scanning, and the estimated time is just the time to put down a prefixed number of layers. What is not included in the simulation is the physical time that the machine needs to wait between one layer and the following. This waiting time is necessary to avoid the case of ending the phase before the right temperature is reached. Table 3 is useful to understand how significant the "waiting for temperature" time is compared with the other phase times (the "wait for temperature" time is included in the cool down time).

\begin{tabular}{|c|c|c|c|c|c|}
\hline \multicolumn{6}{|c|}{ Table 3. Example of process times obtained from the machine log report (in seconds) } \\
\hline Wait for temp & Scan & Recoat & Total build & Warm up & Cool down \\
\hline 1820 & 4742 & 5333 & 10075 & 4916 & 2300 \\
\hline 1622 & 927 & 1068 & 1995 & 4917 & 2102 \\
\hline 1755 & 1129 & 1081 & 2210 & 5211 & 2235 \\
\hline
\end{tabular}

Therefore, the simulation software gives acceptable results in build time estimation, but the 'waiting for temperature' time cannot be omitted and must be included in the model.

\section{Empirical model extraction}

It is possible to extract curves of the build time versus different variables from data collected during the simulated experiments. From these curves, through empirical parameters such as the object dimensions, it is possible to extract mathematical functions to approximate the original curve. 
An advantage of this model is that it is not only valid for the building of one part, but also for many different parts. The model calculates multiple parts timing as it would a single component with a complex shape.

The total time necessary to complete a build can be split as a sum of different times. In particular, referring to Figure 4:

1. Recoating time $\left(t_{z}\right)$ - The time the machine needs to add layers of powder

2. Scanning time $\left(t_{x y}\right)$ - The time the machine needs to sinter the powder passing the laser on the section (area and border scan)

3. Pre and post processing time $\left(t_{H C}\right)$ - The time necessary to heat up and cool down the bed before and after the build phase

In formulas, the total build time $\left(t_{B}\right)$ is:

$$
t_{B}=t_{x y}+t_{z}+t_{H C}
$$

All the time variables presented in the present paper are in seconds. The study follows with the analysis of the three sub-times independently.

\subsection{Recoating time function $\left(t_{z}\right)$}

Figure 7 shows an example of the correlation for geometrical boxes of different heights. The relationship between time and height is linear. 


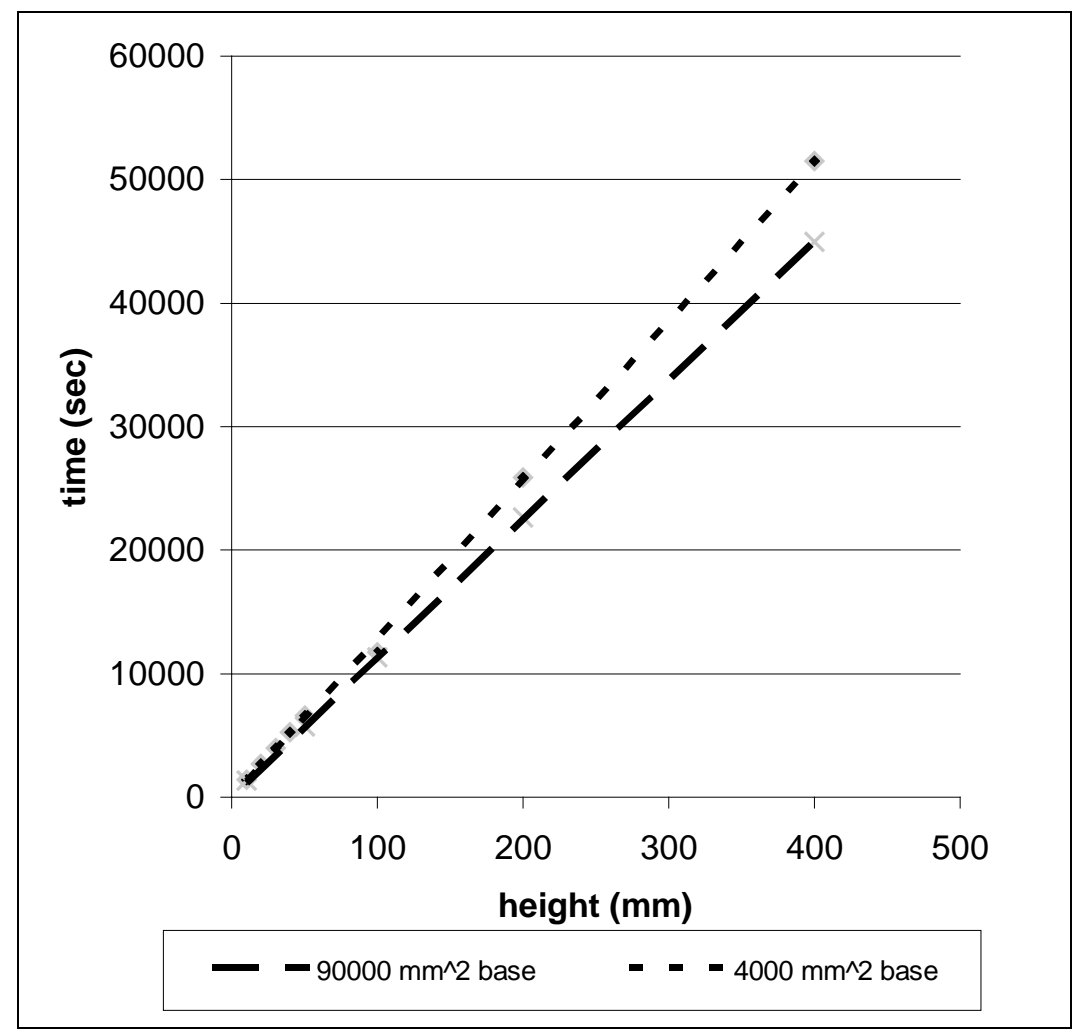

Figure 7. Effect of height on recoating times for two different size boxes

The different gradients of the two linear curves in Figure 7 are due to the time necessary for the laser to reposition in a bed corner after the scanning of a section, as described in paragraph 4.2. In order to describe this gradient, it is necessary to introduce a new variable, the External Packing Ratio ( $\operatorname{Pr}_{e x t} \in[0,1]$ ), which is a measure of the space the part (or parts) needs on the bed. It can be expressed algebraically as:

$$
\operatorname{Pr}_{e x t}=\frac{V_{e x t}}{V_{b e d}}
$$

Where: $V_{\text {ext }}$ is the volume of the minimum geometrical box containing the parts and $V_{\text {bed }}$ is the volume of the entire machine bed (370x330x457mm for the Vanguard).

\begin{tabular}{|l|c|c|c|}
\hline \multicolumn{1}{|c|}{ Table 4. Sample of estimated and real recoating times with relative error } \\
\hline \multicolumn{1}{|c|}{ Part } & $\begin{array}{c}\text { Estimated } \\
\text { Recoating } \\
\text { Time (sec) }\end{array}$ & $\begin{array}{c}\text { Actual } \\
\text { Recoating } \\
\text { Time (sec) }\end{array}$ & $\begin{array}{c}\text { Error } \\
\text { (\%) }\end{array}$ \\
\hline Sphere (Figure 2-a) & 9273 & 9179 & 1.0 \\
\hline Cube (similar to Figure 2-b, but with same volume of Sphere) & 9273 & 8323 & 10.2 \\
\hline Swept Solid (Figure 2-c) & 9193 & 8506 & 7.5 \\
\hline Chain link structure (Figure 3) & 59697 & 45944 & 23.0 \\
\hline $\begin{array}{l}\text { Big Cube (similar to Figure 2-b, but with same volume of Chain } \\
\text { link structure) }\end{array}$ & 70882 & 63162 & 10.9 \\
\hline
\end{tabular}


From the data collected (samples shown in Table 4) the following approximating function was extracted:

$$
t_{z}=\left(180-120 * \operatorname{Pr}_{\text {ext }}\right) * z+400
$$

Table 4 shows some data chosen from the simulated builds, evidencing approximation errors infrequently over $11 \%$, with time overestimation for higher builds. A higher error is present for the Chain link structure, which is a particular case of uncommonly complex shape.

The variable $z$ needs an additional definition as it can have different meanings:

$$
Z=\left\{\begin{array}{l}
z_{P} \text { if _only_one_part_is_present } \\
\max \left\{z_{P_{i}}\right\}_{-} i f \_m o r e_{-} \text {parts_are_arranged_in_one_layer } \\
z_{B} \text {-if_there_are_different_parts_in_multiple_layers }
\end{array}\right.
$$

Where: the subscript $p$ indicates that the variable is referred to the part, while the subscript $B$ means the variable is related to the entire bed in production.

\subsection{Scanning time function $\left(t_{x y}\right)$}

This is the most complex time to estimate, due to the high variability of time for different shapes. The problem is approached by an overestimation and then refined step by step, as listed here:

1. First approximation - The worst case is to assume that the machine, producing a part, has to scan the entire section of the bed. Therefore, the time to build a part is calculated as the time to manufacture a box with the same base of the bed and the height of the part

2. Second approximation - The time to produce the object is the time to produce a box with the same external dimension of the object. This is a good estimate when the part is very compact, without undercuts or internal voids, but it overestimates when the part volume is much less than the bounding box volume

3. Third approximation - An empirical relationship is derived experimentally, refining the second approximation

The experimental function mentioned in point 3 is based on the time to scan the entire bounding box ( $t_{x y \_b}$, as described in point 2$)$ reduced by a factor $\vartheta \in[0,1]$ depending on the real volume of the object $(V)$. Algebraically:

$$
t_{x y}=\vartheta^{*} t_{x y_{-} b o x}
$$

The volume of the object can be either the part volume $\left(V_{P}\right)$ in the case of a single part, or the building volume $\left(V_{B}\right)$ if in the presence of more objects produced at the same time. 
Definition of $\theta$. A new parameter, the compact ratio ( $\mathrm{Cr} \in[0.1]$ ) was introduced to pilot the time equation. The compact ratio is defined as the ratio between the volume of the object (or build) and the volume of its bounding box $\left(V_{\text {ext }}\right)$ :

$$
C r=\frac{V_{B}}{V_{\text {ext }}}
$$

For different compact ratios there are two different relationships connecting the build and bounding box scanning times. The reason to have two different equations describing the same variable is that neither is a good approximation for every case. Two different definitions of the parameter $\theta$ were found experimentally based on the compact ratio: one is polynomial (valid for $\mathrm{Cr}<0.4$, see Equation 7) and one is exponential (valid for Cr>0.4, see Equation 7).

$$
\vartheta=\left\{\begin{array}{l}
0.3422 * C r^{2}+0.2468 * C r+0.45 \_ \text {if _Cr }<0.4 \\
0.417 * e^{0.9283^{*} C r}[\text { if _Cr }>0.4
\end{array}\right.
$$

After different tests the maximum error observed was $12 \%$ and was always an overestimation. An example is reported in Table 5, showing build data with different Compact Ratios.

\begin{tabular}{|c|c|c|c|c|c|c|c|}
\hline \multicolumn{7}{|c|}{ Table 5. Sample data for the function $\theta$ in both Polynomial and Exponential expressions } \\
\hline Part & $\mathbf{C r}$ & $\boldsymbol{\theta}$ & $\begin{array}{c}\text { Estimated } \\
\text { time (sec) }\end{array}$ & Error (\%) & $\boldsymbol{\theta}$ & $\begin{array}{c}\text { Estimated } \\
\text { time (sec) }\end{array}$ & Error (\%) \\
\hline $\begin{array}{c}\text { Chain link } \\
\text { structure } \\
\text { (Figure 3) }\end{array}$ & 0.093 & 0.476 & 89861 & 13.57 & 0.454 & 85854 & $\mathbf{8 . 5 1}$ \\
\hline $\begin{array}{c}\text { Swept Solid } \\
\text { (Figure 2-c) }\end{array}$ & 0.321 & 0.564 & 2064 & 0.73 & 0.562 & 2054 & $\mathbf{0 . 2 6}$ \\
\hline $\begin{array}{c}\text { Sphere } \\
\text { (Figure 2-a) }\end{array}$ & 0.523 & 0.673 & 1586 & $\mathbf{1 2 . 1 1}$ & 0.678 & 1598 & 12.93 \\
\hline $\begin{array}{c}\text { Cube } \\
\text { (Figure 2-b) }\end{array}$ & 1.000 & 1.039 & 1370 & $\mathbf{3 . 9 0}$ & 1.055 & 1391 & 5.51 \\
\hline
\end{tabular}

Time to scan the bounding box. Twenty tests of different boxes were developed in order to find an empirical equation describing the scan time estimation. Most machines are set to scan only in one preferred direction, which is the $x$ direction, and this study includes only this case. The other possibility is alternating the scan of one layer in the $x$ direction with one in the $y$ direction and this needs further study. Due to this preferred $x$ direction, the empirical approximating function discovered is:

$$
t_{x y \_b o x}=\left(0.042 * x^{-0.1809} * A\right) * z
$$


Where $t_{x y \_b o x}$ is the time to scan all the layers of the box, $A$ is the area of the section, $x$ is the length in the $x$ direction and $z$ is the height of the box. Figure 8 shows the error in the estimation using Equation 8, with its maximum always below 10\%.

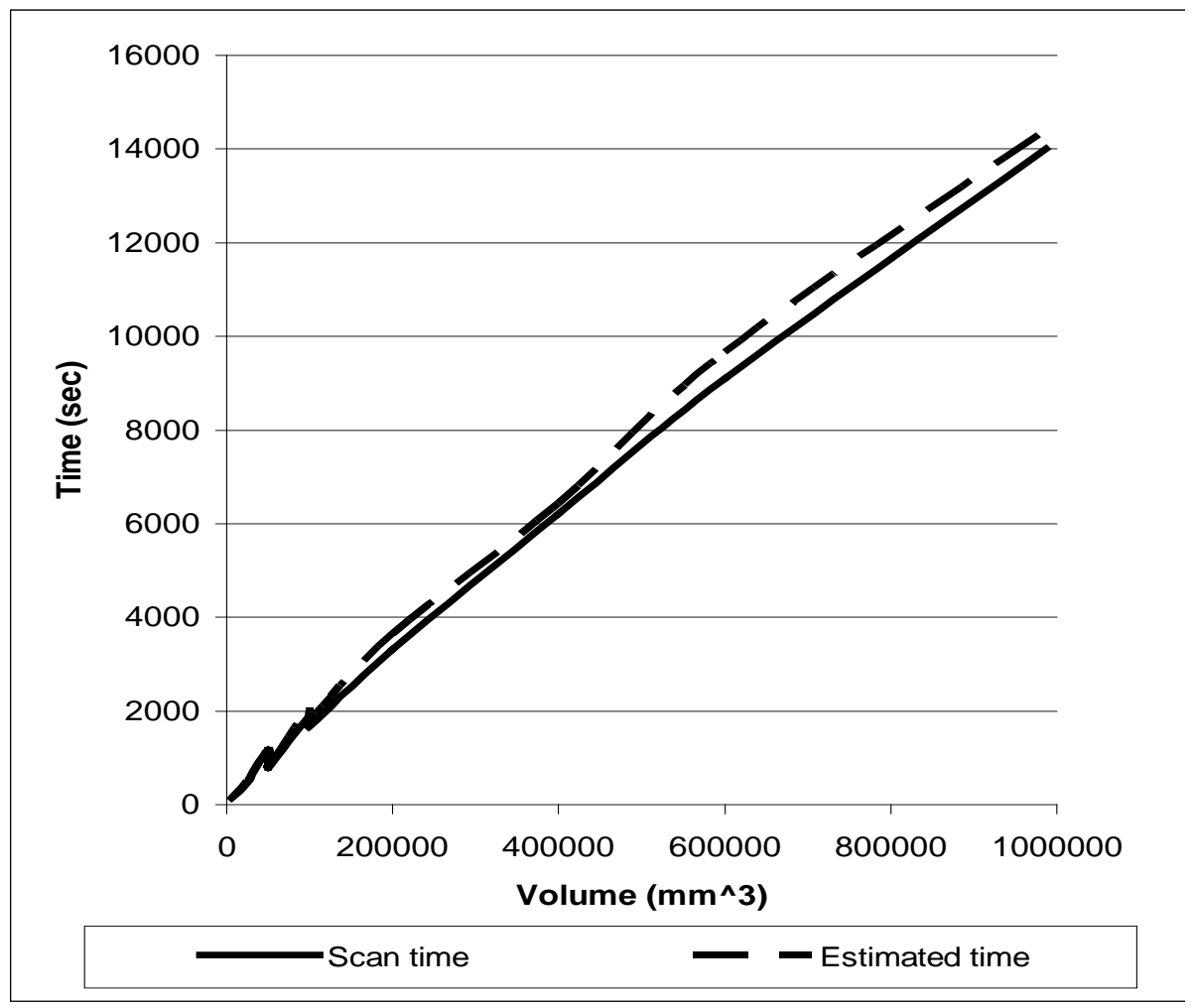

Figure 8. Comparison between the real and the estimated box scan times

\subsection{Heating and cooling time function ( $\left.t_{H C}\right)$}

With reference to the process chain shown in Figure 4, the function dedicated to pre and post processing is constant. Its value depends on the facility in which the machine is run, the external temperature, the speed of the technician to clean the machine and set up the following build. The two processes of gradually warming up and cooling down, adding layers before and after the build phase, are constant and set up by the operator. To give the reader an idea of the value of this constant, $t_{H C}$ is normally around 60 minutes.

\subsection{Summary of equations}

It follows a mathematical description of the model defined by Equations 1-8 summarized in a single expression:

$$
t_{B}=\vartheta *\left(0.042 * x^{-0.1809} * x^{*} y\right) * z+\left(180-120 * \frac{V_{e x t}}{V_{b e d}}\right) * z+400+3600
$$


Where:

$$
\vartheta=\left\{\begin{array}{l}
0.3422 * C r^{2}+0.2468 * C r+0.45 \_ \text {if } \_C r<0.4 \\
0.417 * e^{0.9283^{*} C r} \text { if _Cr }>0.4
\end{array}\right.
$$

and

$$
C r=\frac{V_{B}}{V_{e x t}}
$$

\subsection{Validation of the empirical model}

Referring to the experiments repeated for real on the Vanguard LS machine, mentioned in paragraph 4.4 , it is possible to compare data from the mathematical model created and the real times.

There is a slight underestimation of the scanning time that is balanced by an overestimation of the recoating time. The error associated with the total build time is always below 13\%. Table 6 gives an example of the model accuracy on four random parts. The values reported are the percentage difference between the real and the predicted times, where negative values are underestimations and positive values are overestimations.

Table 6. Percentage differences between simulation and real times for four randomly chosen parts

\begin{tabular}{|c|c|c|}
\hline On Scan (\%) & On Recoat (\%) & On Total build (\%) \\
\hline-5.2 & 27.0 & 13.0 \\
\hline-5.2 & 14.3 & 5.7 \\
\hline-2.8 & 22.1 & 12.4 \\
\hline-3.0 & 20.2 & 8.3 \\
\hline
\end{tabular}

\section{Conclusions}

Previous time estimation studies were undertaken for layer manufacturing processes by different authors (Kamash and Flynn 1995, Chen and Sullivan 1996, Choi and Samevadan 2002). They were focused on very detailed parts of the process (laser scanning velocity etc...), neglecting a general overview of the entire process and a check of the macro time variables (heating and cooling etc...).

The approach of this paper is different. The base of the study is the entire process and a mathematical model is created on empirical data. The variables driving the model are simple to obtain from any CAD software or directly measuring a real object:

- Height

- Volume

- Bounding box volume 
This model is not only valid for the building of one part, but also for many different parts. The model calculates multiple parts timing as it would be a single component with a complex shape.

The model is composed by a series of empirical equations and it slightly overestimates the real production time. This property of never underestimating times makes the model very useful in the case of cost estimation, enabling it to assign indirect costs to the product.

The final accuracy of the time estimator studied could be expressed by a maximum error of $13 \%$ on the total build time, divided in an overestimation of the recoating time (maximum error 27\%) and an underestimation of the scanning time (maximum error 6\%).

A further study could include a refined model; it would be possible to reformulate the approximating equations based on a bigger object sample. Moreover, the approach used for the 3D-Systems ${ }^{\mathrm{TM}}$ Vanguard machine could be extended to other similar LS machines and possibly to different processes.

\section{References}

3D Systems internet web pages at www.3DSystems.com, last visit on December 2004

Build-time estimate program Slitime released by Clemson University, Clemson, South Carolina, 1994

Chen, C. and Sullivan, P., Predicting total build-time and the resultant cure depth of the 3D Stereolithography process, Rapid Prototyping Journal, Volume 2, Number 4, 1966, pp 27-40

Choi, S. and Samevedam, S., Modelling and optimisation of Rapid Prototyping, Computers in Industry 47 (2002) 39-53

Diane, A., Chue, K., Montgomery, D., Optimising Stereolithography throughput, Journal of Manufacturing Systems 16 (4) (1997) 290-303

Grimm T., "User’s guide to Rapid Prototyping”, Society of Manufacturing Engineers, Rapid Prototyping Association of SME, 2004

Hague R.; Campbell I.; Dickens P., Implications on design of rapid manufacturing, Proceedings of the I MECH E Part C Journal of Mechanical Engineering Science, 1 January 2003, vol. 217, no. 1, pp. 25-30(6)

Hopkinson, N., Dickens, P., Analysis of rapid manufacturing-using layer manufacturing processes for production, Proc. Instn. Mech. Engrs Vol 217 Part C: J. Mechanical Engineering Science, IMechE 2003

Hopkinson N.; Dickens P., Rapid prototyping for direct manufacture, Rapid Prototyping Journal, 8 August 2001, vol. 7, no. 4, pp. 197-202(6)

Kamash, T. and Flynn, D., Build time estimator for Stereolithography Machines - A preliminary report, released by Prototype Express, Schaumburg, II, 1995 
Kochan A. (ref.A), "Renault aligns production to market demand”, Assembly Automation, 2003, Volume 23, 4

Kochan A. (ref.B), "Rapid prototyping helps Renault F1 Team UK improve championship prospects”, Assembly Automation, 2003, Volume 23, 4

Marsan A., Allen S., Kulkarni P., Dutta D., An integrated software system for process planning for layered manufacturing, Proceeding of the Solid Freeform Fabrication Symposium, 1997, pp 661-668

Plastic Machine and Auxilaries online, Words of Wisdom: Rapid manufacturing on the horizon, http://www.pma-magazine.com/articles/2003/October/4, last visit on 1309-05

Sherman, L. M., Rapid Prototyping: Pretty Soon, You Won't Be Able To Get Along Without It, Plastics Technology Online (trademark of Gardner Publications, Inc, copyright 2005), readable at http://www.plasticstechnology.com/articles/200102fa2.html, last visit on 13-09-05

Thomson, D., Craword, R., Computational quality measures for evaluation of part orientation in freeform fabrication, Journal of Manufacturing Systems 16 (4) (1997) 273-289

Thomson, D., Craword, R., Optimising part quality with orientation, Proceeding of the Solid Freeform Fabrication Symposium, 1995, pp 362-368

Wohlers T., Wohlers report 2004, Annual Worldwide Progress Report, Wohlers Associates Inc.

Wohlersassociates, physical and mechanical properties datasheet for RM materials, http://wohlersassociates.com/materials2005.pdf, last visit on 13/10/2005

Woodzaik J., Fadel G., Kirschman C., A genetic algorithm for optimising multiple part placement to reduce build-time, Proceeding of the fifth International Conference on Rapid Prototyping, 1994

Zhou, J., Hersovici, D., Parameter tuning and optimisation for SLA rapid prototyping manufacturing processes, Proceeding of international Conference on Manufacturing Automation (ICMA’97), Vol. 2, 1997, pp. 894-902 